\title{
Ulcère gastro-duodénal et tuberculose pulmonaire
}

L'attention a été attirée depuis une dizaine d'années sư les tuberculoses qui se développent après une resection gastrique; survenant après les observations de Lamblíng et Conte sur le « syndrome carenciel grave» des gastrectomisés, et après diverses publications concernant les troubles métaboliques plus profonds que ne le fait supposer Гétat subjectif de ces opérés, il était logique qu'on évoque avant tout une pathogénie nutrítíonnelle. La sévérité de la tuberculose pulmonaire des gastrectomisés - elle emporte un malade sur deux - parle également en faveur d'une moindre resistance des réséqués.

Cependant, il faut se demander jusqu'à quel point Yulcère gastro-duodénal, raison de la gastrectomie, n'est pas en luí-même un facteur prêdísposant à la tuberculose? Chr. Baechler (These de Geneve, no 2715, 1960) s'est efforcé de répondre à cette question sur laquelle il existe fort peu de publications. Si plusieurs auteurs nient la relation étiolo-gique entre ces deux affections, d'autres trouvent un ulcère chez 5 à $10 \%$ des tuberculeux pulmonaires; inversément, certaines statis-tiques (anciennes) donnent jusqu'à $28 \%$ et $55 \%$ d'ulcères chez les tuberculeux pulmonaires; dans un materiel d'autopsies comprenant 105 tuberculoses pulmonaires en activité et 94 ulcères gastro-duodé-naux (Demole et Secretan: Schweiz. Z. Path. Bakt. 21: 553 [1958]), il $\mathrm{y}$ avait coexistence de deux affections dans 13 cas, ce qui est très hautement significatif, et non une simple coincidence.

Parmi 454 ulcéreux diagnostiqués en 11 ans à la Clinique médicale de Geneve, Baechler trouve 25 tuberculoses (non connues antérieure-ment), soit 5,57\%; chez 500 dyspeptiques témoins, la proportion des tuberculoses n'est que de $2,4 \%$; et là encore, 1 'analyse statistique prouve que Vassociation avec Гulcère gastro-duodénal n'est pas fortuite. Enfin, en procédent à une enquête chez 62 ulcéreux traités ambula-toirement avant 1958 (done avec deux ans de recul au moins), on apprend que 7 malades ont été opérés, 1 est décédé; et sur les 54 res-tant (32 ulcères duodénaux et 22 gastriques), 3 ont présenté un episode de tuberculose depuis la guérison (subjective) de leur ulcère. Et la proportion $(5,56 \%)$ est exactement la même que dans la série hospitalière!

\section{Editorial}

131

Certes, les troubles nutritionnels de Fulcéreux (temporaires, pendant les périodes douloureuses) sont bien différents de ceux du gastrectomisé, qui sont permanents et indépendants de 1 'alimentation. II n'en reste pas moins qu'en pratique:

$1^{\circ}$ on doit considérer la tuberculose comme une complication possible de $\Gamma$ ulcère gastroduodénal, en rechercher la coexistence ou $\Gamma$ apparition dans revolution de la maladie ulcéreuse; $2^{\circ}$ avant d'envisager une gastrectomie, il faut faire jouer un role aux antecedents bacillaires dans les contre-indications opératoires; $3^{\circ}$ les poumons des réséqués seront surveillés périodiquement, surtout chez les gastrectomisés quine reprennent pas de poids ou présentent des troubles intestinaux. M. D.

Referate - Abstracts - Analyses 
Bearbeitet von: - Prepares par:

L. Demling, Erlangen; M. Demole, Geneve; H. Kapp, Basel; JV. Lloret, Barcelona;

$\mathrm{Ph}$. Secretan, Geneve; A. Tosoni-Pittoní, Paris; B. Wíssmer, Geneve

V. Leber - Foie

Sailer, S. und Braunsteiner, H.: Uber eine neue, sehr eínfache Methode zur Bestim-mung der Serumcholinesteraseaktivität und ihre klinische Bedeutung. Klin. Wschr. 1959: 986.

Die Autoren geben einen methodisch einfachen Kurztest zur Bestimmung der

Serumcholinesteraseaktivität an. Hierdurch wird es möglich, ein Ferment routine-mäßig zu

bestimmen, das bei entzündlichen Erkrankungen der Leber in einem Maße vermindert ist, daß

bieraus diagnostische und differential-diagnostische Schlüsse (gegenüber dem

Okklusionsikterus) gezogen werden können.

Wernze, H.: Klinische Untersuchungen zur Frage der Leberschädigung durch neuere androgene und anabole Steroide. Dtsch. med. Wschr. 1960: 2237.

An 36 Lebergesunden wurde in drei- bis vierwòchigen Behandlungsperioden der Einfluß neuer androgener Steroide auf die Leberfunktion gepriift. Die vom 17 alpha-Methyl-testosteron

abgeleiteten und oral wirksamen Verbindungen wie Methandro-stenolon (Dianabol) und 9 alphaFluor-11 beta-hydroxy-Methyl-testosteron (Ultandren) rufen in Abhängigkeit von der Dosis eine Verzögerung der Brom-thaleinausscheidung und eine geringe Erhöhung der Serum-

Glutaminsäure-Oxal-essigsäure-ïransaminase liervor. Der Effekt ist reversibel. 19-

Nortestosteron-phenylproprionat (Durabolin) läßt im Vergleich zu den beiden am C-17-Atom substituierten Verbindungen gleichartige Wirkungen auf die Leberfunktion nicht erkennen. Die Probleme, die sich im Hinblick auf den Arzneimittelikterus hieraus ergeben, werden diskutiert. 